\title{
Designing Automatic Guided Device of Books
}

\author{
Yulius Advent Putra ${ }^{1,1}$, Porman Pangaribuan ${ }^{1}$, and Rizki Ardianto Priramadhi ${ }^{1}$ \\ ${ }^{1}$ Assistant Lecturer, School of Electrical Engineering (Telkom University, Indonesia)
}

\begin{abstract}
There are several methods returning scattered books in library, such as asking visitors to put them back to the bookshelf, recruiting more employees, or creating system that can return the books automatically. But, by using the system, visitors no need to walk to certain bookshelf. The system itself called Automatic Guided Device included of Automatic Guided Vehicle (AGV), RFID tag, scissor-lift, and book thruster. Every books have RFID tags which contains the book database. There are name of books and shelf location inside of the database. Visitors just need scan the book(s) and laid on the device, then the system will begin to operate. After that, this Automatic Guided Device sensor equipped will start its journey and go through to the location of bookshelf by following tracked line on the floor. To show them, it uses ASCII Table in the C Source Code Program. This table is to represent information substitutes which contains certain number, then it will be declared as the bookshelf location spot. After reaching certain distance, scissor-lift lifts as high as the table. Then scissor-lift stops, while the book thruster removing the book from device into bookshelf. So, this system not only returning the books without any manual operation but also can do more things such as lifting and putting the books automatically at once. Based on several tests, AGD reaches at certain spot within an average $60 \%$ of successfulness by using ASCII Table numbering format.
\end{abstract}

\section{Introduction}

Most visitors are not only read a kind of book, but also several books, and usually left the books when they have finished reading, so it will make scattered books on the table. There are several methods to return all of the scattered books, first, asking visitors to put them back to the bookshelf, then second, recruiting new employees, and the third one is creating system that can return the books automatically. The first method shows that the notice from librarians will not give any attention to the visitors, and sometimes it is ignored by them. The second one is not suitable because the library is already has enough staffs. Third, creating a system that can return the books automatically which is called Automatic Guided Device (AGD). Using this device, this system not only returning the books without any manual operation but also can do more things such as lifting and putting the books at once. So, by comparing all of methods, we consider that the third one should be more effective. Also, this method applying automatic guided of books without any manual operation, so it will keep the book tidiness. It confusing another visitor if they didn't find any book they wanted. In other words, the book circulation is restricted. So, we hope that this system will

${ }^{1}$ Corresponding author: yuliusadventp@gmail.com 
make visitors are easier looking for their books. Besides, the librarians don't need to worry of all visitors forgetting to return their books because it has been done by automatic guided device.

\section{Direct Observation}

Direct observation is a directly contact method to get any valid information based on true range, in case, inside Open Library Telkom University. The data is obtained from librarian's database center which contain the number of visitors a day and book status whether it's returned to shelf or read only by visitor.

\subsection{Existing Method and Their Limitation}

The amount of visitors and borrowed books each day are relative. But there's a big difference between the sum of books list. Based on obtained data, returned-books is always more than read-only books every day. There were 852 borrowed books per day and 11 staffs, which means that a staff must returned it approximately 85 books per day. Now, there are 79,506 books, 1031 borrowed books per day, and 11 staffs, so there are 102 of books for a staff must to do the same thing.

Below is their limitation of existing system:

- Book circulation (returned or borrowed books) is restricted.

- Most visitors can't return the book to proper shelf

- Shelving is only done when the library is closed or before it opens

\subsection{Proposed System}

This Designing Automatic Guided Device of Books help both librarian staff and visitors in putting back the books. Advantages of using this device:

- Keep the bookshelves tidiness

- Decreasing the restricted book circulation

- Visitors just scan the books then the device automatically operates, so visitors no need to walk to proper shelf.

\section{Design Of System}

\subsection{Block Diagram}

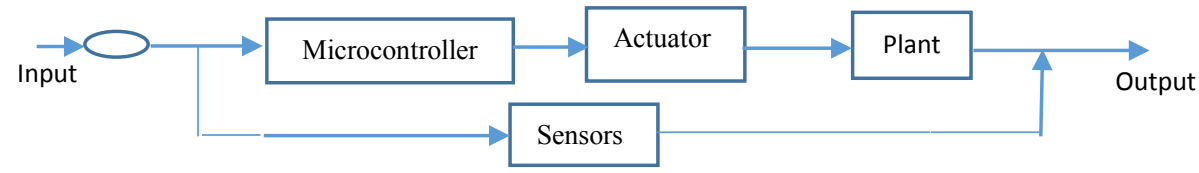

Fig 1. AGD Control System Block Diagram

$\begin{array}{ll}\text { - } & \text { Input } \\ \text { - } & \text { Microcontroller } \\ \text { - } & \text { Actuators } \\ \text { - } & \text { Plants } \\ \text { - } & \text { Sensor } \\ \text { - } & \text { Output }\end{array}$

: Scanned books

: Raspberry Pi 3 and Arduino Nano

: DC Motors

: AGV, scissor-lift, book thruster

: IR sensor

: Moving AGD through the tracked lines 
The book is scanned, then it will be processed by Raspberry Pi 3 microcontroller for database reading. Microcontroller which have found the database will transmit its data to Arduino Nano by serial communication to operate DC motor and activate the sensor. The DC motors drive the AGV to proper shelf while the sensor reading through the tracked line that indicate where should the device moved. After it reaches the proper shelf, AGV stops and then scissor-lift motor start to operate, changing rotation-to-vertically linear motion until it reaches certain height of shelf. After that, scissor-lift stops and then book thruster begins to push the lowest book until the book itself are removed from device to proper shelf. Next, the book thruster and scissor-lift are consecutively going back to their initial position to continue the journey.

\subsection{Architectural Design}

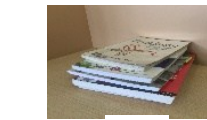

1

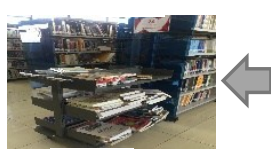

7

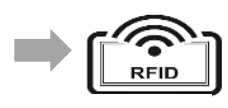

2

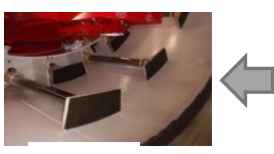

6

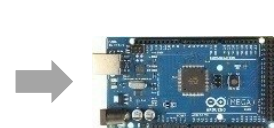

3

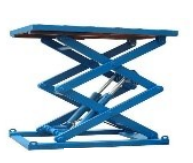

5

Fig.2. Architectural Diagram of AGD System
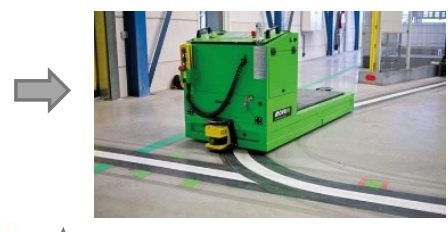

4

\subsubsection{Scattered Books}

This is the main problem from some visitors who don't return their books after they read them. The books are laid on table only, and need to be returned.

\subsubsection{RFID (Radio Frequency Identification)}

There are 2 main components in RFID system, Tag and Reader. There are 2 main components in RFID Tag, IC (Integrated Circuit) as a transponder, and Antenna as a receiver also sending RF signal ${ }^{[4]}$. Each book is inserted by a tag and need to be scanned. The system, scanned books will be identified by the reader. For books RFID tag is used as identifier which reduces manual interference for returning and issuing books ${ }^{[2]}$. But in some libraries barcode is used for book identification [3].

\subsubsection{Arduino Nano}

Arduino Nano is one of microcontroller board which is based on the ATmega 328. It is a microcontroller platform that can easily connected into many computers, so users can program any ATmega chip ${ }^{[1]}$. The system needs more inputs, and this microcontroller can fulfill them. Also, the microcontroller contains the database which shows the bookshelf location and type of book.

\subsubsection{Automatic Guided Vehicle (AGV)}

Some examples of AGV device products are being optimized, for example intelligent navigation research in warehousing ${ }^{[5]}$, and 
otherwise, there is also an AGV design that is made to have spring absorption with a double spring solution ${ }^{[6]}$. But the writer's project is about optimizing AGV into returning books automatically by tracked line.

\subsubsection{Scissor-Lift}

${ }^{[3]}$ Scissor lift mechanism is one kind of lifter using hydraulic system which can help lifting up vertical easily. To lift up, there's a motor which are connected to metal sheets, changing rotation into vertically linear motion. Using this method as lifting book is because can be set its height.

\subsubsection{Book Thruster}

To remove books from device into bookshelf is using thruster which made of long basic bolt connected to a motor.

\subsubsection{Proper Shelf}

The device moving through its point which is proper shelf. This is where the book should be put, based on the database.

\section{Result}

The data below present about AGD's depart and arrived time, also the result about how many books, their weight, and how long the scissor lift to do up-lifting and down-lifting experiment. The scissor-lift load is negligible.

Table 1. Test Result of AGD's Depart Time and Arrived Time

\begin{tabular}{|c|c|c|c|c|}
\hline Test & Distance (cm) & Depart Time (s) & $\begin{array}{l}\text { Arrived } \\
\text { Time (s) }\end{array}$ & $\begin{array}{c}\text { Additional } \\
\text { Information }\end{array}$ \\
\hline 1 & 200 & 6.19 & 6.73 & SUCCESS \\
\hline 2 & 200 & 6.24 & - & NOT SUCCESS \\
\hline 3 & 200 & 6.16 & - & NOT SUCCESS \\
\hline 4 & 200 & 6.07 & 6.63 & SUCCESS \\
\hline 5 & 200 & 6.11 & 6.68 & SUCCESS \\
\hline 6 & 200 & 6.04 & - & NOT SUCCESS \\
\hline 7 & 200 & 6.13 & 6.75 & SUCCESS \\
\hline 8 & 200 & 6.06 & 6.69 & SUCCESS \\
\hline 9 & 200 & 6.14 & - & NOT SUCCESS \\
\hline 10 & 200 & 6.18 & 6.78 & SUCCESS \\
\hline \multicolumn{2}{|r|}{ Average } & 6.132 & 6.71222 & \\
\hline
\end{tabular}

Based on 10 tests that have been carried out, not all have been successful, as in tests $2,3,6$, and 9 . It is because the failure of sensor readings. In addition, a great friction factor between the freewheel and the floor due to the influence of the load, resulting in AGD sometimes are not successfully moving backwards to follow tracked line. This is the reason why arrived time longer than when the device moving forward. The human error factor, like error reading, and the movement of the device system also involves the time 
value are various. Six of the ten tests were successfully carried out, so in other words, the success percentage is $60 \%$.

Table 2. Relationship between Number of Books, Weight of Book/s (kg), and Time Needed for Up and Down Lifting

\begin{tabular}{|c|c|c|c|c|c|}
\hline \multirow[b]{2}{*}{ No } & \multirow{2}{*}{$\begin{array}{c}\text { Number } \\
\text { of } \\
\text { Books }\end{array}$} & \multirow[b]{2}{*}{$\begin{array}{c}\text { Weight } \\
\text { (kg) }\end{array}$} & \multicolumn{2}{|c|}{ Time (s) } & \multirow[b]{2}{*}{ Additional Information } \\
\hline & & & $\begin{array}{l}\text { Up- } \\
\text { lift }\end{array}$ & $\begin{array}{l}\text { Down- } \\
\text { lift }\end{array}$ & \\
\hline 1 & - & - & 29.9 & 28.75 & Scissor-lift operates smoothly. \\
\hline 2 & 1 & 0.5 & 32.93 & 28.66 & \multirow{5}{*}{$\begin{array}{l}\text { When the motor operate at } \mathrm{t}=5 \mathrm{~s} \\
\text { it always indicates that the motor } \\
\text { is hardly lifting the scissor lift in } \\
\text { rotary-to-linear motion because of } \\
\text { the book's weight and scissor-lift } \\
\text { load itself. }\end{array}$} \\
\hline 3 & 2 & 0.825 & 33.17 & 29.84 & \\
\hline 4 & 3 & 1.275 & 34.22 & 28.74 & \\
\hline 5 & 4 & 3.175 & 46.84 & 32.21 & \\
\hline 6 & 5 & 4.35 & 53.41 & 29.73 & \\
\hline 7 & 6 & 5.25 & - & - & $\begin{array}{l}\text { Scissor-lift won't lift up because } \\
\text { of excessive load. }\end{array}$ \\
\hline
\end{tabular}

According to Table 4.1, the bigger the load, the longer it takes the time lifting the scissor-lift. We take the book randomly, because not all the books have the same weight. They're relative. Scissor-lift maximum load capacity is under 5 kilograms, so it's not lifted if we put more than its maximum. Meanwhile, time needed for down-lifting is nearly close. They are different because watching-time human error. In addition, there're several other factors, such as scissor-lift high friction, bolt's thread, lifting movement. The friction makes hard moving of scissor-lift, the higher its friction, the longer time it will takes. High friction will make the device quickly damaged and it slowly leaves the rust. Bolt's thread also determines the vertical distance, the longer thread's distant, the higher scissor-lift lifting vertically in a spin. Besides, lifting movement gives an effect to scissor-lift. The device which is not steady while lifting takes more time to reach certain position.

\section{Conclusion}

1. Many cases of scattered books in the library need to be solved in several methods, and we prefer to AGD considering to their limitation.

2. To find out the position of the bookshelf, use the ASCII table to help align or AGD stepping.

3. The average percentage of success for AGD to run on the line on the floor is $60 \%$, this is due to the influence of several external factors.

4. On scissor lifts, the heavier the load of the book, the more uplifting it takes, but there's no affection in down-lifting.

\section{References}

1. Wolfram Donat "Learn Raspberry Pi Programming with Python". 2014 ed.: Apress, c2014 
2. Tao Sun, Shuming Tang, Jinqiao Wang, and Weibin Zhang, "A Robust Lane Detection Method for Autonomous Car-Like Robot”, 2013 Fourth International Conference on Intelligent Control and Information Processing (ICICIP,) Beijing, China June 9 - 11, 2013.

3. J.Y. Tigli and M.C. Thomas, "Use of Multi Agent Systems for Mobile Robotics Control", IEEE 1994.

4. Susy d'Hont, "The Cutting Edge of RFID Technology and Applications for Manufacturing and Distribution", Texas Instrument TIRIS, 2002.

5. https://ieeexplore.ieee.org/document/8242766/

6. https://ieeexplore.ieee.org/document/8078899/ 